\title{
Fontes alternativas e doses de nitrogênio no milho safrinha em sucessão à soja ${ }^{1}$
}

\author{
Sidedressing nitrogen alternative sources and rates on out-of-season corn after \\ soybean
}

\author{
Rogério Peres Soratto ${ }^{2 *}$, Magno Pereira ${ }^{3}$, Tiago Aparecido Mingotti da Costa $^{3}$ e Vinícius do Nascimento \\ Lampert $^{3}$
}

\begin{abstract}
Resumo - A produtividade do milho safrinha pode ser aumentada com a adubação nitrogenada em cobertura mesmo quando cultivado em sucessão à soja. No entanto, existem inconsistências dos resultados especialmente quanto às fontes e doses a serem empregadas nessa modalidade de cultivo. Com o objetivo de avaliar o efeito de fontes e doses de nitrogênio em cobertura no milho safrinha, cultivado após soja no sistema plantio direto, conduziu-se o experimento em um Latossolo Vermelho distrófico, em Chapadão do Céu (GO). O delineamento experimental foi o de blocos ao acaso, em esquema fatorial 4 x 4, com quatro repetições. Os tratamentos foram constituídos pela combinação de quatro fontes (uréia, sulfato de amônio, uréia extrusada com produtos amiláceos (Amiréia ${ }^{\circledR} 180 \mathrm{~S}$ ) e sulfonitrato de amônio com inibidor de nitrificação (Entec $\left.{ }^{\circledR} 26\right)$ ) e quatro doses de nitrogênio $\left(0 ; 30 ; 60\right.$ e $\left.120 \mathrm{~kg} \mathrm{ha}^{-1}\right)$. A interação fonte $\mathrm{x}$ dose não foi significativa para nenhuma das variáveis avaliadas. A aplicação de nitrogênio na forma de entec proporcionou maiores teores de nitrogênio na folha do milho safrinha que o sulfato de amônio e a amiréia. A produtividade de grãos do milho safrinha foi maior quando o nitrogênio em cobertura foi fornecido na forma de sulfato de amônio, em comparação com a amiréia. A aplicação de nitrogênio em cobertura aumentou os teores de nitrogênio e enxofre na folha, altura da planta, diâmetro do colmo, número de espigas por planta e grãos por espiga, massa de 1.000 grãos e produtividade de grãos do milho safrinha, em sucessão à soja, independentemente da fonte utilizada.
\end{abstract}

Palavras-chave - Zea mays. Plantas-Efeito do nitrogênio. Plantio direto.

\begin{abstract}
Out-of-season corn yield can be increased by nitrogen sidedressing fertilization even when sowed after soybean harvest. However, there is result inconsistency especially as to nitrogen sources and rates for corn in the cropping system. In order to evaluate the effect of sources and rates of sidedressed nitrogen application on out-of-season corn grown after soybean crop, an experiment was carried out on an Acrustox, in Chapadão do Céu (GO). A randomized complete block design, in 4x4 factorial scheme, and four replications was used. Treatments included four sources (urea, ammonium sulfate, urea extruded with starch (Amiréia $\left.{ }^{\circledR} 180 \mathrm{~S}\right)$, and ammonium sulfonitrate with nitrification inhibitor $\left(\operatorname{Entec}^{\circledR} 26\right)$ ) and four rates of nitrogen $\left(0 ; 30 ; 60\right.$ and $\left.120 \mathrm{~kg} \mathrm{ha}^{-1}\right)$. The source $\mathrm{x}$ rates interaction was not significant for any of the variables evaluated. Sidedressing nitrogen application as entec promoted higher leaf nitrogen concentration than ammonium sulfate and amiréia. Corn grain yield was higher when fertilized with sidedressing nitrogen as ammonium sulfate than amiréia. Sidedressing nitrogen increased leaf nitrogen and sulfur concentrations, plant height, stem diameter, number of ear per plant, number of grains per ear, weight of 1,000 grains, and grain yield of out-of-season corn grown after soybean crop, regardless of the source used.
\end{abstract}

Key words - Zea mays. Plants-Nitrogen effect. No-tillage.

\footnotetext{
* Autor para correspondência

${ }^{1}$ Recebido para publicação em 09/11/2009; aprovado em 20/10/2010

Parte do trabalho de Iniciação Científica do segundo autor desenvolvido com bolsa PIBIC

${ }^{2}$ Departamento de Produção Vegetal (Agricultura), Faculdade de Ciências Agronômicas, Universidade Estadual Paulista, Botucatu-SP, Brasil, soratto@fca.unesp.br

${ }^{3}$ Universidade Estadual de Mato Grosso do Sul, Unidade Universitária de Cassilândia, Cassilândia-MS, Brasil, magnouems@bol.com.br,

tiagomingotti@hotmail.com, vinlampert@bol.com.br
} 


\section{Introdução}

A segunda safra ou safrinha representa cerca de $30 \%$ da produção total de milho (Zea mays L.) do Brasil (CONAB, 2009). Devido à viabilidade econômica e aos benefícios agronômicos associados à rotação de culturas, como aumento da palhada, redução de pragas e doenças, além de permitir melhor aproveitamento dos insumos agrícolas, os produtores têm investido em tecnologias para o cultivo do milho safrinha (PEREIRA et al., 2009).

$\mathrm{O}$ nitrogênio $(\mathrm{N})$ é fundamental no metabolismo vegetal, participando diretamente na biossíntese de proteínas e clorofilas, sendo um dos nutrientes que apresenta os efeitos mais significativos no aumento da produtividade da cultura do milho (BÜLL, 1993). Devido a sua dinâmica no solo, apresenta um complexo manejo, sendo, geralmente, o elemento mais caro no sistema de produção da cultura do milho (BASTOS et al., 2008; CANTARELLA; MARCELINO, 2008).

Uma questão ainda não esclarecida é a dose de $\mathrm{N}$ que deve ser aplicada no milho safrinha. As incertezas climáticas, especialmente a disponibilidade hídrica, e a implantação da cultura em sucessão à soja (Glycine $\max ($ L.) Merr.) são os principais fatores associados à dificuldade nessa tomada de decisão. Segundo Coelho e França (1995), para uma produtividade média de $5.800 \mathrm{~kg} \mathrm{ha}^{-1}$ de grãos, são extraídos aproximadamente $100 \mathrm{~kg} \mathrm{ha}^{-1}$ de $\mathrm{N}$, sendo que cerca de $75 \%$ é exportada pelos grãos. Embora existam relatos de resposta do milho safrinha a adubação nitrogenada de cobertura (BROCH; FERNANDES, 2000; KAPPES et al., 2009; MAR et al., 2003; SOUZA; SORATTO, 2006), perdas que ocorrem, principalmente, por volatilização podem reduzir a eficiência da adubação nitrogenada. Esse problema é agravado pela utilização da uréia como fonte de $\mathrm{N}$, pela aplicação em época com ocorrência irregular de chuvas e pela presença de palhada sobre a superfície do solo, como, muitas vezes, acontece no cultivo de safrinha na região Centro-Oeste (SOUSA; LOBATO, 2004).

As perdas por volatilização quando se utiliza o sulfato de amônio não são grandes (LARA CABEZAS et al., 2008), porém, essa fonte normalmente apresenta um custo por unidade de $\mathrm{N}$ muito superior à uréia. Uma alternativa seria a proteção da partícula da uréia com produtos menos higroscópicos que permitam aplicá-la na superfície do solo, favorecendo sua penetração de forma controlada e estimulando o processo de hidrólise no interior do solo, reduzindo as perdas de $\mathrm{N}$ na forma de $\mathrm{NH}_{3}$ (BONO et al., 2006).

A proteção da uréia pode ser obtida por extrusão, que consiste na união da uréia com a molécula de amido gelatinizado, mediante exposição à pressão, temperatura e umidade por um determinado tempo, dando origem a um produto denominado amiréia (PIRES et al., 2004). Outra possibilidade é a utilização de fontes de liberação lenta ou de inibidores da nitrificação, como o 3,4-dimethilpirazolfosfato (DMPP), que permitem suprimento de $\mathrm{N}$ durante o ciclo da cultura e redução das perdas (BARTH et al., 2001; ZERULLA et al., 2001). Na Europa, a adição de DMPP ao sulfonitrato de amônio aumentou a produtividade do milho por aumentar o aproveitamento do N (PASDA et al., 2001). Contudo, ainda existem dúvidas sobre a resposta da cultura do milho safrinha, cultivado após soja no sistema plantio direto, à doses dessas fontes alternativas de $\mathrm{N}$.

Neste contexto, objetivou-se, com este trabalho, avaliar o efeito de fontes e doses de $\mathrm{N}$ em cobertura no milho safrinha cultivado após soja no sistema plantio direto.

\section{Material e métodos}

O trabalho de pesquisa foi conduzido em campo comercial na Fazenda Elo III, localizada no município de Chapadão do Céu, GO (18³5'42” S, 5247'59” W e altitude de $802 \mathrm{~m}$ ). As precipitações pluviais registradas durante a fase experimental estão apresentadas na Figura 1.

O solo do local é um Latossolo Vermelho distrófico (EMBRAPA, 2006), manejado há seis anos no sistema plantio direto, com a rotação algodão/ milho/soja, nas últimas safras. Antes da instalação do experimento, foi coletada amostra composta de 10 subamostras, na camada de 0-0,20 m, para determinação das características químicas do solo, cujos resultados foram: $\mathrm{MO}=32,0 \mathrm{~g} \mathrm{dm}^{-3} ; \mathrm{pH}\left(\mathrm{CaCl}_{2} 0,01 \mathrm{~mol} \mathrm{~L}^{-1}\right)=$ 5,$4 ; \mathrm{P}($ resina $)=8,0 \mathrm{mg} \mathrm{dm}^{-3} ; \mathrm{K}^{+} ; \mathrm{Ca}^{2+} ; \mathrm{Mg}^{2+}$ e $\mathrm{H}+\mathrm{Al}=$ 5,$8 ; 51,0 ; 18,0$ e $35,0 \mathrm{mmol}_{\mathrm{c}} \mathrm{dm}^{-3}$, respectivamente; V $=68 \%$; e S-SO ${ }_{4}^{-2}=2,0 \mathrm{mg} \mathrm{dm}^{-3}$.

Após a colheita da soja, foi realizada a dessecação das plantas presentes na área com a utilização de herbicida glyphosate (1,44 $\mathrm{kg} \mathrm{ha}^{-1}$ do i.a.). A semeadura do milho foi realizada em sistema plantio direto sobre os restos culturais da soja, no dia 24/02/2006, utilizando o híbrido comercial DKB 979, em espaçamento de 0,80 m entre linhas e 60.000 plantas ha-1. O DKB 979 é um híbrido duplo, de ciclo precoce (845 graus dias) e recomendado para o cultivo de safrinha na região. A adubação de semeadura foi realizada de acordo com os critérios adotados pelo produtor, aplicando-se $150 \mathrm{~kg} \mathrm{ha}^{-1} \mathrm{da}$ fórmula $\mathrm{N}-\mathrm{P}_{2} \mathrm{O}_{5}-\mathrm{K}_{2} \mathrm{O} 08-20-10+8 \%$ de S. A emergência ocorreu em 01/03/2006. 


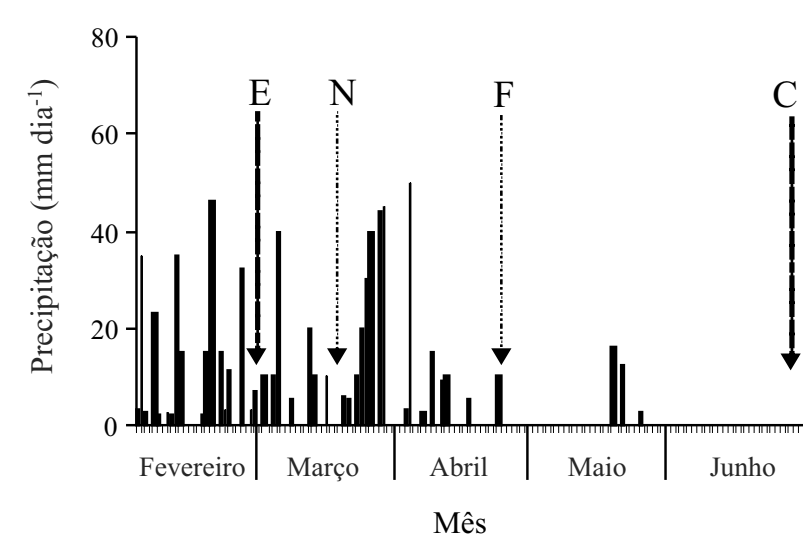

Figura 1 - Precipitação pluvial registrada na área do experimento, durante o período de fevereiro a junho de 2006 , Chapadão do Céu (GO). Datas de emergência (E), aplicação de $\mathrm{N}$ em cobertura $(\mathrm{N})$, florescimento masculino (F) e ponto de colheita (C)

O delineamento experimental utilizado foi o de blocos casualizados, em esquema fatorial $4 \times 4$, com quatro repetições. As fontes testadas foram: uréia (45\% de $\mathrm{N})$, sulfato de amônio ( $20 \%$ de $\mathrm{N}$ e $24 \%$ de S), uréia extrusada com produtos amiláceos (Amiréia ${ }^{\circledR} 180 \mathrm{~S}$, Pajoara Indústria e Comércio, Campo Grande-MS, com $28 \%$ de $\mathrm{N}$ e $3 \%$ de $\mathrm{S}$ ) e sulfonitrato de amônio com inibidor de nitrificação DMPP (Entec ${ }^{\circledR} 26$, Compo do Brasil S.A., Florianópolis-SC, com 26\% de N, 18,5\% na forma amoniacal e 7,5\% na forma nítrica, e $13 \%$ de $\mathrm{S}$ ). As doses utilizadas foram: 0; 30; 60 e $120 \mathrm{~kg} \mathrm{ha}^{-1}$ de N, aplicados em cobertura. Cada unidade experimental foi constituída por 6 linhas de $6 \mathrm{~m}$ de comprimento.

A aplicação do $\mathrm{N}$ foi realizada 17 dias após a emergência (DAE), quando as plantas apresentavam 56 folhas totalmente expandidas, distribuindo-se o adubo sobre a superfície do solo ao lado e aproximadamente $10 \mathrm{~cm}$ das fileiras de plantas.

Para o controle de lagarta-do-cartucho (Spodoptera frugiperda) foinecessário realizaraplicações dos inseticidas metomil (107,5 $\mathrm{g} \mathrm{ha}^{-1}$ do i.a.), no dia 13/03/2006, metomil (107,5 $\mathrm{g} \mathrm{ha}^{-1}$ do i.a.) e novalurom (10 $\mathrm{g} \mathrm{ha}^{-1}$ do i.a.), no dia 23/03/2006, e novalurom (12 $\mathrm{g} \mathrm{ha}^{-1}$ do i.a.), no dia $01 / 04 / 2006$.

O florescimento masculino (pendoamento) ocorreu em 24/04/2006. Nesta ocasião, coletou-se, ao acaso, 15 folhas (terço central da folha da base da espiga), em cada parcela (CANTARELLA et al., 1996). O material foi seco em estufa a $65^{\circ} \mathrm{C}$ por 72 horas. Em seguida, foram moídas e submetidas à análise química para determinação dos teores de $\mathrm{N}$ e $\mathrm{S}$, segundo os métodos descritos por Malavolta et al. (1997).
No dia 12/05/2006, foram realizadas, em 10 plantas por parcela, as determinações de altura da planta (distância do solo até a inserção do pendão), altura da inserção da primeira espiga (distância do solo até o ponto de inserção da primeira espiga) e diâmetro do colmo (medida no primeiro internódio da base da planta).

Por ocasião da colheita, que ocorreu em 31/06/2006, foram determinadas as seguintes variáveis: população final de plantas, número de espigas por planta, número de grãos por espiga, massa de 1.000 grãos e produtividade de grãos. Para a avaliação da produtividade de grãos, foram colhidas, manualmente, as plantas contidas em duas fileiras de $4 \mathrm{~m}$ de comprimento da área útil de cada parcela. Após a debulha, os grãos foram pesados e, posteriormente, calculada a produtividade em $\mathrm{kg} \mathrm{ha}^{-1}$. Os valores massa de 100 grãos e a produtividade de grãos foram padronizados a $130 \mathrm{~g} \mathrm{~kg}^{-1}$ de umidade (base úmida).

Os resultados foram submetidos à análise de variância. As médias referentes às fontes de $\mathrm{N}$ foram comparadas pelo teste de Tukey a 5\% de probabilidade, enquanto os efeitos das doses de $\mathrm{N}$ foram avaliados por meio de análise de regressão, adotando-se como critério para escolha do modelo a magnitude dos coeficientes de regressão significativos ao nível de $5 \%$ de probabilidade pelo teste $\mathrm{t}$.

\section{Resultados e discussão}

Houve adequada distribuição pluviométrica na fase inicial do desenvolvimento da cultura com boas precipitações até próximo do florescimento masculino, inclusive logo após a aplicação do N em cobertura (FIG. 1).

$\mathrm{O}$ teor de $\mathrm{N}$ na folha foi influenciado pelas fontes e doses de $\mathrm{N}$ aplicadas em cobertura (TAB. 1). Verificou-se que a aplicação de entec proporcionou maiores teores de $\mathrm{N}$ do que as fontes sulfato de amônio e amiréia, porém, não diferiu estatisticamente da uréia. As doses de $\mathrm{N}$ em cobertura aumentaram linearmente os teores desse elemento na folha do milho, independente da fonte utilizada (FIG. 2A). Mar et al. (2003) também verificaram aumento no teor foliar de $\mathrm{N}$ no milho safrinha após soja, em função da aplicação de $\mathrm{N}$ em cobertura. Contudo, mesmo no tratamento testemunha, o teor de $\mathrm{N}$ estava na faixa considerada adequada (27-35 $\mathrm{g} \mathrm{kg}^{-1}$ ) por Cantarella et al. (1996), este fato pode ser resultado da disponibilização de razoáveis quantidades do nutriente mediante o processo de mineralização dos restos da cultura da soja e da matéria orgânica do solo, que no presente solo era de $32,0 \mathrm{~g} \mathrm{dm}^{-3}$. A decomposição da palhada deixada pela colheita da soja, anterior à semeadura do milho safrinha, normalmente é muito rápida, devido à baixa relação $\mathrm{C} / \mathrm{N}$ da leguminosa, à temperaturas elevadas e às boas condições hídricas do solo. 
Tabela 1 - Teores de N e S na folha, altura da planta, altura de inserção da $1^{\text {a }}$ espiga e diâmetro do colmo do milho safrinha em função de fontes e doses de $\mathrm{N}$ em cobertura

\begin{tabular}{|c|c|c|c|c|c|}
\hline Fonte de $\mathrm{N}$ & $\begin{array}{l}\text { Teor de } \mathrm{N} \mathrm{na} \\
\text { folha }\left(\mathrm{g} \mathrm{kg}^{-1}\right)\end{array}$ & $\begin{array}{l}\text { Teor de } \mathrm{S} \mathrm{na} \\
\text { folha }\left(\mathrm{g} \mathrm{kg}^{-1}\right)\end{array}$ & $\begin{array}{l}\text { Altura da planta } \\
(\mathrm{m})\end{array}$ & $\begin{array}{c}\text { Altura de inserção da } \\
1^{\text {a }} \text { espiga }(\mathrm{m})\end{array}$ & $\begin{array}{l}\text { Diâmetro do } \\
\text { colmo (mm) }\end{array}$ \\
\hline Entec & $33,6 \mathrm{a}^{1}$ & 2,6 & 2,21 & 1,00 & 21,5 \\
\hline Sulfato de amônio & $30,8 \mathrm{~b}$ & 2,5 & 2,21 & 1,01 & 21,6 \\
\hline Amiréia & $29,4 \mathrm{~b}$ & 2,5 & 2,16 & 0,99 & 20,8 \\
\hline Uréia & $31,5 \mathrm{ab}$ & 2,6 & 2,16 & 0,97 & 21,3 \\
\hline \multicolumn{6}{|l|}{ Teste F } \\
\hline Fonte $(\mathrm{F})$ & $5,837 * *$ & $0,172 \mathrm{~ns}$ & $1,913 \mathrm{~ns}$ & $1,078 \mathrm{~ns}$ & $2,457 \mathrm{~ns}$ \\
\hline \multicolumn{6}{|l|}{ Dose (D) } \\
\hline Reg. Linear & $8,221 * *$ & $0,001 \mathrm{~ns}$ & $5,439 *$ & $3,464 \mathrm{~ns}$ & $18,240 * *$ \\
\hline Reg. Quadrática & $3,566 \mathrm{~ns}$ & $6,547^{*}$ & $0,580 \mathrm{~ns}$ & $0,336 \mathrm{~ns}$ & $7,922 * *$ \\
\hline Interação (F x D) & $1,254 \mathrm{~ns}$ & $0,410 \mathrm{~ns}$ & $0,732 \mathrm{~ns}$ & $0,881 \mathrm{~ns}$ & $0,974 \mathrm{~ns}$ \\
\hline CV (\%) & 9,4 & 12,2 & 3,6 & 5,3 & 4,3 \\
\hline
\end{tabular}

Médias seguidas de letras distintas na coluna (fontes) diferem entre si pelo teste de Tukey $(P=0,05)$. ${ }^{*}$, * e ns são respectivamente, significativo a $1 \%, 5 \%$ e não significativo pelo teste $\mathrm{F}$

Apenas as doses de $\mathrm{N}$ influenciaram no teor de $\mathrm{S}$ na folha do milho, independentemente da fonte utilizada, proporcionando incremento até a dose máxima estimada de $65,8 \mathrm{~kg} \mathrm{ha}^{-1}$ de N (TAB. 1 e FIG. 2B). Casagrande e Fornasieri Filho (2002) também verificaram aumento no teor de $\mathrm{S}$ na folha do milho com o aumento das doses de $\mathrm{N}$ na forma de uréia. Contudo, em todos os tratamentos, os teores de $\mathrm{S}$ estavam dentro da faixa considerada adequada para a cultura (CANTARELLA et al., 1996) e as relações entre os teores de $\mathrm{N}$ e $\mathrm{S}$ estavam dentro da faixa indicada por Arnon (1975) para assegurar máxima produção potencial de matéria seca e proteínas, ou seja, entre 12 e 15 para 1 . A ausência de efeito das fontes no teor de $\mathrm{S}$ na folha, provavelmente, foi devido à aplicação de $12 \mathrm{~kg} \mathrm{ha}^{-1}$ do nutriente via adubação de base e liberação do nutriente mediante a decomposição dos restos da cultura da soja.

A altura da planta e o diâmetro do colmo foram incrementados pela doses de $\mathrm{N}$ em cobertura, independentemente da fonte utilizada; contudo, a altura de inserção da primeira espiga não foi afetada pelos fatores estudados (TAB. 1, FIG. 2C e 2D). Plantas adequadamente nutridas em $\mathrm{N}$ têm maior desenvolvimento vegetativo, uma vez que o nutriente influencia diretamente a divisão e expansão celular e o processo fotossintético (BÜLL, 1993). O colmo funciona como estrutura de reserva, ocorrendo translocação de fotoassimilados do colmo para os grãos (MAGALHÃES; JONES, 1990). Assim, maiores diâmetros de colmos, normalmente, se correlacionam positivamente com maiores produtividades de grãos, como observado neste trabalho $(\mathrm{r}=0,44 ; P<0,001)$. Mar et al. (2003) e Souza e Soratto (2006) também verificaram aumento da altura de plantas do milho safrinha, em sucessão à soja, em resposta à aplicação de N em cobertura. Contudo, Meira et al. (2009) não verificaram efeito da aplicação de diferentes fontes (sulfato de amônio, uréia e entec) no diâmetro do colmo do milho irrigado.

A população de plantas não foi alterada pelas fontes e doses de $\mathrm{N}$, sendo que a média de todos os tratamentos ao final do ciclo foi de 54.330 plantas ha' ${ }^{-1}$ (TAB. 2).

$\mathrm{O}$ número de espigas por planta foi aumentado de forma linear em razão das doses de $\mathrm{N}$, não tendo sido influenciado pelas fontes (TAB. 2 e FIG. 3A). De acordo com Fancelli e Dourado Neto (2004), no estágio de quatro folhas começa a ser definido o potencial produtivo da planta de milho, pois se inicia o processo de diferenciação floral e a deficiência de N, nesse período, pode interferir no número de estruturas reprodutivas. 

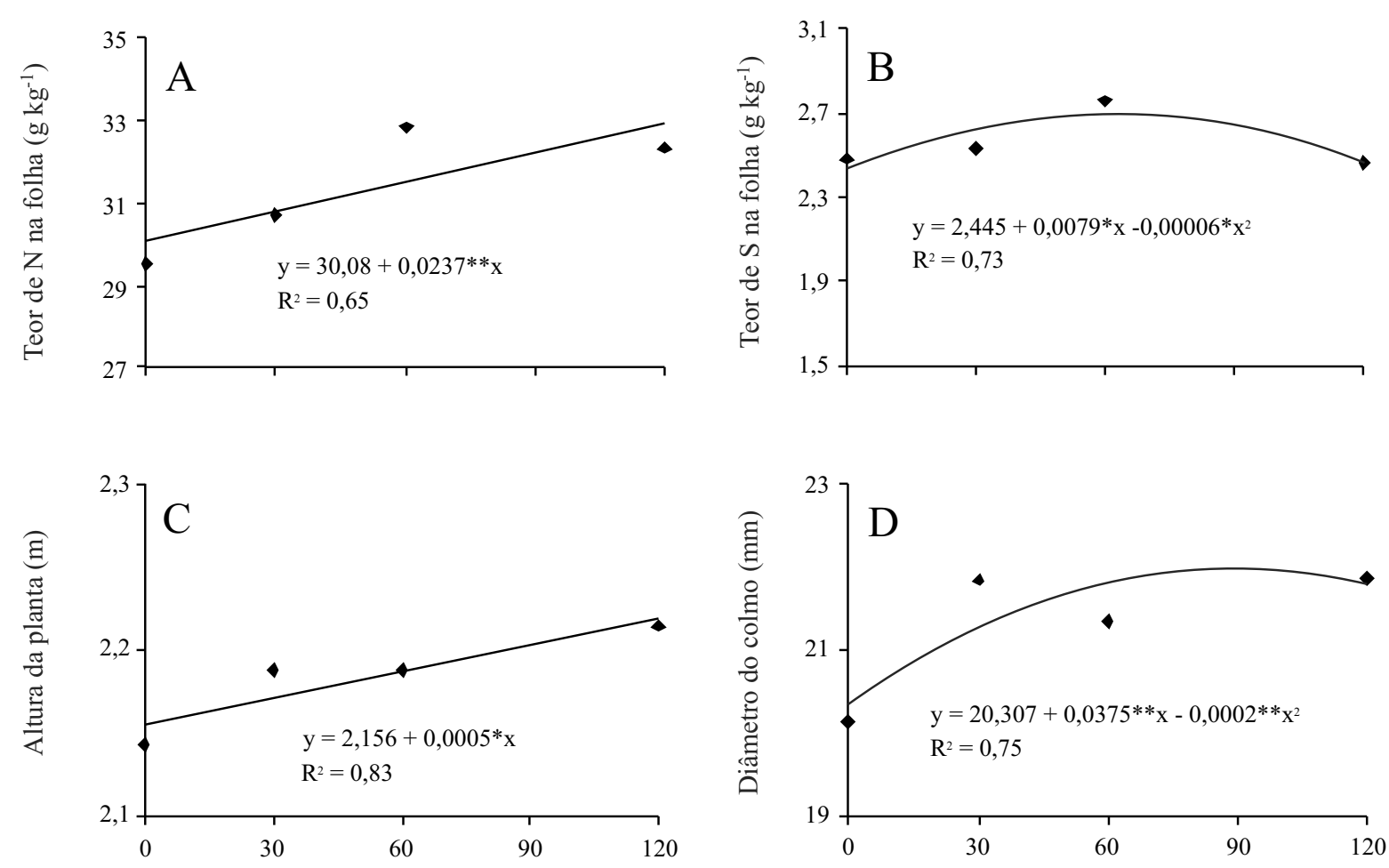

$\mathrm{N}$ em cobertura $\left(\mathrm{kg} \mathrm{ha}^{-1}\right)$

Figura 2 - Teores de N (A) e S (B) na folha, altura da planta (C) e diâmetro do colmo (D) do milho safrinha em função da aplicação de doses de $\mathrm{N}$ em cobertura. Média de quatro fontes. ${ }^{*} \mathrm{e} * *$ são significativos a $5 \%$ e $1 \%$, respectivamente, pelo teste $\mathrm{t}$

Tabela 2 - População final de plantas, número de espigas por planta e de grãos por espiga, massa de 1.000 grãos, produtividade de grãos e teor de proteína nos grãos do milho safrinha em função de fontes e doses de $\mathrm{N}$ em cobertura

\begin{tabular}{lcccccc}
\hline Fonte de N & $\begin{array}{c}\text { População } \\
\text { final de plantas } \\
\text { plantas ha-1) }^{-1}\end{array}$ & $\begin{array}{c}\text { No de espigas } \\
\text { por planta }\end{array}$ & $\begin{array}{c}\text { No de grãos } \\
\text { por espiga }\end{array}$ & $\begin{array}{c}\text { Massa de } \\
1.000 \text { grãos (g) }\end{array}$ & $\begin{array}{c}\text { Produti- } \\
\text { vidade de } \\
\text { grãos (kg ha-1) }\end{array}$ & $\begin{array}{c}\text { Teor de } \\
\text { proteína no } \\
\text { grão (\%) }\end{array}$ \\
\hline Entec & $53.874,00$ & 0,99 & 425,300 & 242,000 & $4.623 \mathrm{ab}$ & 9,600 \\
Sulfato de amônio & $54.264,00$ & 0,99 & 427,900 & 247,200 & $4.952 \mathrm{a}$ & 9,200 \\
Amiréia & $55.046,00$ & 0,99 & 426,300 & 239,500 & $4.582 \mathrm{~b}$ & 9,500 \\
Uréia & $54.134,00$ & 0,98 & 428,400 & 242,200 & $4.832 \mathrm{ab}$ & 9,400 \\
\hline Teste F & - & - & - & - & - & - \\
Fonte (F) & $0,524 \mathrm{~ns}$ & $0,249 \mathrm{~ns}$ & $0,067 \mathrm{~ns}$ & $0,849 \mathrm{~ns}$ & $3,899^{*}$ & $1,429 \mathrm{~ns}$ \\
Dose (D) & & & & & & \\
Reg. Linear & $0,132 \mathrm{~ns}$ & $9,583^{* *}$ & $13,680^{* *}$ & $6,957^{*}$ & $5,414^{*}$ & $2,123 \mathrm{~ns}$ \\
Reg. Quadrática & $0,033 \mathrm{~ns}$ & $0,197 \mathrm{~ns}$ & $0,179 \mathrm{~ns}$ & $8,002^{* *}$ & $2,372 \mathrm{~ns}$ & $0,231 \mathrm{~ns}$ \\
Interação (F x D) & $0,439 \mathrm{~ns}$ & $0,400 \mathrm{~ns}$ & $0,558 \mathrm{~ns}$ & $0,763 \mathrm{~ns}$ & $1,298 \mathrm{~ns}$ & $1,533 \mathrm{~ns}$ \\
\hline CV (\%) & 5,1 & 2,9 & 5,3 & 5,8 & 7,5 & 5,3 \\
\hline
\end{tabular}

Médias seguidas de letras distintas na coluna (fontes) diferem entre si pelo teste de Tukey $(P=0,05)$. **, * e ns são respectivamente, significativo a $1 \%, 5 \%$ e não significativo pelo teste $\mathrm{F}$ 

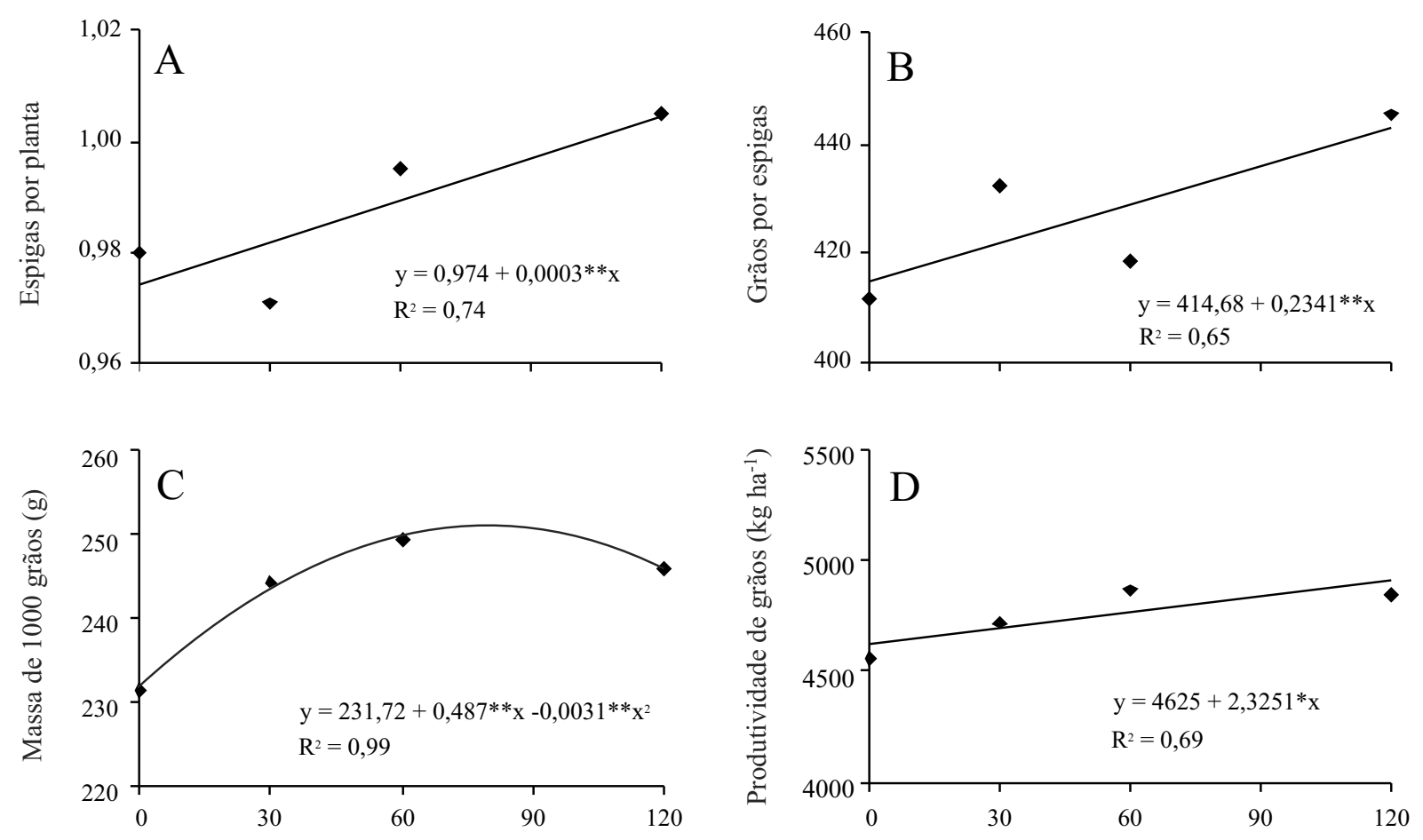

$\mathrm{N}$ em cobertura $\left(\mathrm{kg} \mathrm{ha}^{-1}\right)$

Figura 3 - Número de espigas por planta (A) e de grãos por espiga (B), massa de 1.000 grãos (C) e produtividade de grãos (D) do milho safrinha em função da aplicação de doses de $\mathrm{N}$ em cobertura. Média de quatro fontes. * e ** são significativos a $5 \%$ e $1 \%$, respectivamente, pelo teste $\mathrm{t}$

O número de grãos por espiga aumentou de forma linear em razão da aplicação de $\mathrm{N}$, independentemente da fonte utilizada (TAB. 2 e FIG. 3B). Para Ernani et al. (2005), o suprimento insuficiente de $\mathrm{N}$ durante o estádio de diferenciação floral pode reduzir o número de óvulos nos primórdios da espiga e, com isso, diminuir a produtividade de grãos. Um importante papel do $\mathrm{N}$ em assegurar alta produtividade de milho está no estabelecimento da capacidade do dreno reprodutivo. Apesar da capacidade do dreno reprodutivo ser função do número e do tamanho dos grãos, o número de grãos por espiga se correlaciona mais intensamente com a produtividade de grãos de milho que qualquer outro componente da produção (BELOW, 2002). Souza e Soratto (2006) também obtiveram incremento no número de grãos por espiga do milho safrinha cultivado após soja com aplicação de $\mathrm{N}$ em cobertura, independentemente da fonte utilizada.

A massa de 1.000 grãos foi aumentada pela aplicação de doses de N (TAB. 2 e FIG. 3C), não sendo afetada pelas fontes. Observa-se que o aumento dessa variável foi até a dose máxima estimada de $78,5 \mathrm{~kg} \mathrm{ha}^{-1} \mathrm{de}$ $\mathrm{N}$. O N desempenha importante papel como constituinte essencial dos aminoácidos, principais integrantes de proteínas. Assim, como a formação dos grãos depende de proteínas na planta, a massa dos grãos e a produtividade estão diretamente relacionadas com o suprimento de $\mathrm{N}$ (BELOW, 2002).

A aplicação de $\mathrm{N}$ na forma de sulfato de amônio proporcionou maior produtividade de grãos de milho, em relação à amiréia, porém, não diferiu das demais fontes (TAB. 2). Broch e Fernandes (2000) também verificaram aumento da produtividade do milho safrinha com o fornecimento de $\mathrm{N}$ e $\mathrm{S}$ via sulfato de amônio. Houve incremento linear da produtividade do milho safrinha com a aplicação de $\mathrm{N}$, cujo aumento foi de $7,6 \%$ em relação ao tratamento sem aplicação de $\mathrm{N}$ em cobertura, independentemente da fonte utilizada (FIG. 3D). Bastos et al. (2008) obtiveram aumento da produtividade do milho até a dose de $180 \mathrm{~kg} \mathrm{ha}^{-1}$ de N. Resultados semelhantes foram obtidos por Mar et al. (2003) e Souza e Soratto (2006), que observaram aumento da produtividade de grãos do milho safrinha com a aplicação de até $120 \mathrm{~kg} \mathrm{ha}^{-1}$ de N. Kappes et al. (2009) observaram incremento significativo na produtividade do milho com aplicação de $70 \mathrm{~kg} \mathrm{ha}^{-1}$ de $\mathrm{N}$, independentemente da fonte utilizada (sulfato 
de amônio, uréia e entec). Meira et al. (2009) não verificaram efeito dessas fontes na produtividade do milho irrigado.

Houve reduzida precipitação pluvial a partir do florescimento masculino da cultura do milho (FIG. 1). Penariol et al. (2003) destacam que a produtividade do milho pode ficar comprometida se a deficiência hídrica coincidir com o período do florescimento, fase que determina a quantidade de óvulos a serem fecundados, e, por consequência, a produção de grãos. Segundo Cruz et al. (2006), o déficit hídrico pode ocasionar danos em todos os estádios de desenvolvimento, sendo que na fase de enchimento de grãos afeta o metabolismo da planta e o fechamento de estômatos, reduzindo a taxa fotossintética e, consequentemente, a produção de fotossimilados e sua translocação para os grãos. Isso justifica as menores produtividades obtidas no presente experimento em relação às relatadas para o milho safrinha por Mar et al. (2003) e Kappes et al. (2009), que tiveram melhor disponibilidade hídrica inclusive após o florescimento da cultura.

O teor de proteína bruta nos grão não foi influenciado pelos fatores estudados, com os valores variando de 9,2 a $9,6 \%$ (TAB. 2). A não-significância dos resultados pode ter sido influenciada pelo $\mathrm{N}$ advindo, principalmente, da decomposição da matéria orgânica e dos restos da cultura da soja, já que mesmo na testemunha os teores de $\mathrm{N}$ na folha estavam na faixa considerada adequada para a cultura (CANTARELLA et al., 1996).

Apesar dos baixos índices de precipitação pluvial ocorridos a partir do final de abril, a produtividade de grãos obtida foi satisfatória para a condição de safrinha. Os resultados indicam que é possível aumentar a produtividade do milho safrinha com a aplicação de $\mathrm{N}$ em cobertura, mesmo quando esse é cultivado em sucessão à soja, e, quando a aplicação é realizada em período com boa ocorrência de chuvas, não existem vantagens na utilização de fontes alternativas como Entec $^{\circledR} 26$ e Amiréia ${ }^{\circledR} 180 \mathrm{~S}$, em relação à uréia.

\section{Conclusões}

1. A aplicação de $\mathrm{N}$ na forma de entec proporcionou maiores teores de $\mathrm{N}$ na folha do milho safrinha que $\mathrm{o}$ sulfato de amônio e a amiréia;

2. A produtividade de grãos do milho safrinha foi maior quando o $\mathrm{N}$ em cobertura foi fornecido na forma de sulfato de amônio, em comparação com a amiréia;

3. A aplicação de $\mathrm{N}$ em cobertura proporcionou aumento nos teores de $\mathrm{N}$ e $\mathrm{S}$ na folha, na altura da planta, diâmetro do colmo, no número de espigas por planta e grãos por espiga, na massa de 1.000 grãos e na produtividade de grãos do milho safrinha, em sucessão à soja, independentemente da fonte utilizada.

\section{Agradecimentos}

Ao Sr. Adriano Loeff, proprietário da Fazenda Elo III, pela permissão de realização do experimento em sua área. Ao CNPq, pela concessão de bolsa de Produtividade em Pesquisa para o primeiro autor.

\section{Referências}

ARNON, I. Mineral nutrition of maize. Bern: International Potash Institute, 1975. $452 \mathrm{p}$.

BASTOS, E. A. et al. Doses e formas de parcelamento de nitrogênio para a produção de milho sob plantio direto. Revista Ciência Agronômica, v. 39, n. 02, p. 275-280, 2008.

BELOW, F. E. Fisiologia, nutrição e adubação nitrogenada do milho. Informações Agronômicas, n. 99, p. 7-12, 2002.

BARTH, G., TUCHER, S. Von; SCHMIDHALTER, U. Influence of soil parameters on the effect of 3,4-dimethylpyrazolephosphate as a nitrifycation inhibitor. Biology and Fertility of Soils, v. 34, n. 01, p. 98-102, 2001.

BONO, J. A. M.; SETTI, J. C. A.; SPEKKEN, S. S. P. O nitrogênio protegido como alternativa de fertilizante para o uso no plantio da cultura do algodão. Ensaios e Ciência, v. 10, n. 01, p. 39-45, 2006.

BROCH, D. L.; FERNANDES, C. H. Efeito da adubação de plantio e de cobertura na produtividade do milho safrinha. Informações Agronômicas, n. 89, p. 1-3, 2000.

BÜLL, L. T. Nutrição mineral do milho. In: BÜLL, L. T.; CANTARELLA, H. (Ed.). Cultura do milho: fatores que afetam a produtividade. Piracicaba: POTAFOS, 1993. p. 63-145.

CANTARELLA, H.; MARCELINO, R. Fontes alternativas de nitrogênio para a cultura do milho. Informações Agronômicas, n. 122, p. 12-14, 2008.

CANTARElla, H.; RAIJ, B. Van; CAMARGO, C. E. O. Cereais. In: RAIJ, B. Van, et al. (Ed.). Recomendações de adubação e calagem para o Estado de São Paulo. 2. ed. Campinas: Instituto Agronômico, 1996. p. 45-71. (Boletim Técnico, 100).

CASAGRANDE, J. R. R.; FORNASIERI FILHO, D. Adubação nitrogenada na cultura do milho safrinha. Pesquisa Agropecuária Brasileira, v. 37, n. 01, p. 33-40, 2002.

COElHO, A. M.; FRANÇA, G. E. de. Seja o doutor do seu milho: nutrição e adubação. 2. ed. Piracicaba: Potafos, 1995. 9 p.

COMPANHIA NACIONAL DE ABASTECIMENTO (CONAB). Safras 1990/91 a 2008/09: série histórica. Brasília. 
Disponível em: <http:// www.conab.gov.br/conabweb/index. php? $\mathrm{PAG}=131>$. Acesso em: 6 out. 2009.

CRUZ, J. C. et al. Manejo da cultura do Milho. Sete Lagoas: Embrapa Milho e Sorgo, 2006. (Circular técnica, 87).

EMPRESABRASILEIRADEPESQUISA AGROPECUÁRIA (EMBRAPA). Centro Nacional de Pesquisa de Solos. Sistema brasileiro de classificação de solos. 2. ed. Rio de Janeiro, 2006. 306 p.

ERNANI, P. R. et al. A forma de aplicação da uréia e dos resíduos vegetais afeta a disponibilidade de nitrogênio. Ciência Rural, v. 35, n. 02, p. 360-365, 2005.

FANCELLI, A. L.; DOURADO NETO, D. Produção de milho. 2. ed. Guaíba: Agropecuária, 2004. 360 p.

KAPPES, C. et al. Influência do nitrogênio no desempenho produtivo do milho cultivado na segunda safra em sucessão à soja. Pesquisa Agropecuária Tropical, v. 39, n. 03, p. 251-259, 2009.

LARA CABEZAS, W. A. R. et al. Utilização de uréia em misturas com sulfato de amônio ou com gesso na cultura de milho. Revista Brasileira de Ciência do Solo, v. 32, n. 06, p. 2343-2353, 2008.

MAGALHÃES, P. C.; JONES, R. Aumento de fotoassimilados na taxa de crescimento e peso final dos grãos de milho. Pesquisa Agropecuária Brasileira, v. 25, n. 12, p. 1747-1754, 1990.

MALAVOLTA, E.; VITTI, G. C.; OLIVEIRA, S. A. Avaliação do estado nutricional de plantas: princípios e aplicações. 2. ed. Piracicaba: Potafos, 1997. 319 p.

MAR, G. D. et al. Produção do milho safrinha em função de doses e épocas de aplicação de nitrogênio. Bragantia, v. 62, n. 02, p. 267-274, 2003.
MEIRA, F. A. et al. Fontes e épocas de aplicação do nitrogênio na cultura do milho irrigado. Semina: Ciênicas Agrárias, v. 30, n. 02, p. 275-284, 2009.

PASDA, G.; HÄHNDEL, R.; ZERULLA, W. Effect of fertilizers with the new nitrification inhibitor DMPP $(3,4-$ dimethylpyrazole phosphate) on yield and quality of agricultural and horticultural crops. Biology and Fertility of Soils, v. 34, n. 02, p. 85-97, 2001.

PENARIOL, F. G. et al. Comportamento de cultivares de milho semeadas em diferentes espaçamentos entre linhas e densidades populacionais, na safrinha. Revista Brasileira de Milho e Sorgo, v. 02, n. 02, p. 52-60, 2003.

PEREIRA, J. L. A. R. et al. Cultivares, doses de fertilizantes e densidades de semeadura no cultivo de milho safrinha. Ciência e Agrotecnologia, v. 33, n. 03, p. 676-683, 2009.

PIRES, A. V. et al. Substituição do farelo de soja por uréia ou amiréia na dieta de bovinos de corte confinados. Pesquisa Agropecuária Brasileira, v. 39, n. 09, p. 937-942, 2004.

SOUSA, D. M. G. de; LOBATO, E. Adubação com nitrogênio, In: Cerrado: correção do solo e adubação, Planaltina: Embrapa Cerrados, 2002. $416 \mathrm{p}$.

SOUZA, E. de F. C. de; SORATTO, R. P. Efeito de fontes e doses de nitrogênio em cobertura, no milho safrinha, em plantio direto. Revista Brasileira de Milho e Sorgo, v. 05, n. 03, p. 387-397, 2006.

ZERULLA, W. et al. 3,4 Dimethylpyrazole phosphate (DMPP) a new nitrification inhibitor for agriculture and horticulture: An introduction. Biology and Fertility of Soils, v. 34, n. 01, p. 79-84, 2001. 